\title{
EL BOOM DE LAS FRANQUICIAS EN EL PERÚ ¿ES TIEMPO DE UNA REGULACIÓN JURÍDICA O AÚN NO?
}

Yuly Ludeña Almeyda ${ }^{1}$

\begin{abstract}
RESUMEN
Este artículo está basado en una reciente tesis denominada "Conveniencia de una regulación jurídica para los sistemas de franquicias en el Perú", el cual pretende dar información acerca de la actual y real situación del mercado peruano de franquicias. La idea principal es hacer un análisis de los problemas legales existentes alrededor del sector que no generan seguridad jurídica a las partes intervinientes; personas que a consecuencia de la ausencia de una legislación especial, se han visto envueltas en conflictos legales y desprotegidos, se vieron forzados a tomar decisiones finales injustas. Estos conflictos obstaculizan un mejor y acelerado crecimiento sostenible, pues ha sido demostrado que en países en donde la franquicia ha sido constituida como una institución jurídica, ha superado barreras económicas impensables. De acuerdo a la investigación, este artículo muestra las razones resumidas por las que la tesis propone artículos legales que deben ser integrados en un cuerpo regulatorio para contrarrestar la actual problemática y a manera predictiva, evitar serios problemas que podrían venir en un futuro cercano.
\end{abstract}

PALABRAS CLAVE

Mercado Peruano de Franquicias. Conflictos Legales. Seguridad Jurídica. Legislación Especial.

\section{ABSTRACT}

This article is based on a recent theory called "Convenience of regulating franchise systems in Peru," which aims at providing updated and real information about the situation of the Peruvian franchises market. The main idea is to analyze the existing legal problems in an industry that does not instill legal certainty for the parties involved. As a result of the absence of special legislation, some people have been involved in legal disputes and were forced to make unfair final decisions because they were unprotected. These disputes hinder better, rapid, sustainable growth. There is evidence showing that in countries where the franchise has been established as a legal institution, franchises have overcome unthinkable economic barriers. Based on research, this article shows the reasons outlined by the thesis that proposes legal articles to be integrated into a regulatory body to counteract the current problems and hence avoid serious problems that could arise in the near future.

\section{KEY WORDS}

Franchaises Peruvian Market. Legal Conflicts. Legal Certainty. Special Laws.

\section{A MODO DE INTRODUCCIÓN}

En el mundo existe el consenso de que el formato de franquicias es actualmente considerado como la vía más idónea para la expansión de negocios, y esto se puede decir no sólo por las características innatas de este formato de negocio, que ofrece de por sí innumerables ventajas tanto para franquiciantes como para franquiciados; sino también, por el acelerado crecimiento del sector en los últimos tres (3) años, pues cada vez son más las empresas interesadas en franquiciar su concepto de negocio, como son más las personas interesadas en saber sobre qué trata este novedoso negocio llamado "Franquicias".

En nuestro país, desde el año 2009 surge la etapa denominada "Boom de las Franquicias" caracterizada porque el sector

1 Abogada titulada en la Universidad Femenina del Sagrado Corazón (UNIFÉ). Autora de la tesis denominada "Conveniencia de una regulación jurídica para los sistemas de franquicias en el Perú". Estudios de Postgrado en Gestión de Mypes en la Escuela de Administración de Negocios para Graduados (ESAN); Investigadora y Asistente Editorial en la "Franquiguia Perú 2012”, primer directorio de franquicias en el Perú, yuludalmeyda@gmail.com 
muestra una gran efervescencia que se manifiesta tanto de la conversión de franquicias locales como la importación constante de franquicias extranjeras.

Estadísticas actualizadas al 2012, demuestran que en entre los años 2009 al 2012, sólo las franquicias nacionales aumentaron en más de $100 \%$, independientemente de las franquicias extranjeras que llegaron al país para operar su marca. Siendo así, al 2012 las franquicias nacionales ascendían a la cifra de 106. Hasta el 2009, según Promperú, las franquicias con capital peruano sumaban 48 empresas. Por lo que hasta la fecha, la cifra de éstas se ha incrementado en más del $100 \%$. Para mayor comprensión y exactitud de estudio, se clasificó en los siguientes siete sectores con el número exacto de franquicias en cada uno:

\begin{tabular}{|l|c|c|}
\hline SECTORES & $\begin{array}{l}\text { NRO. } \\
\text { FRANQUICIAS }\end{array}$ & PORCENTAJE \\
\hline GASTRONOMÍA & 71 & $67 \%$ \\
\hline ARTESANÍA - JOYERÍA- REGALOS & 7 & $7 \%$ \\
\hline ESTÉTICA, BELLEZA Y SALUD & 8 & $7 \%$ \\
\hline INDUMENTARIA Y ACCESORIOS & 6 & $6 \%$ \\
\hline \hline EDUCACIÓN & 4 & $4 \%$ \\
\hline FERRETERÍA Y CONSTRUCCIÓN & 2 & $2 \%$ \\
\hline \hline SERVICIOS ESPECIALIZADOS & 8 & $7 \%$ \\
\hline \hline TOTAL & 106 & $100 \%$ \\
\hline Fuente: Front Consulting Perú & & \\
\hline
\end{tabular}

Se puede nombrar a muchas que formalmente han iniciado su proceso de expansión local, teniendo muchas sedes en la capital y algunas en provincias con relativo éxito, como son Corporación Educativa Pamer, El Pollo Real, Frutix, La Gran Fruta, Las
Canastas, entre otros. Así como otros conceptos nacionales se han logrado exportar y hoy se las encuentra en muchos países, es el caso de Chinawok, Bembos, La Rosa Nautica, Pardo's Chicken, Astrid \& Gastón, Osaka, entre otros.
En el siguiente cuadro se puede observar la gran expansión de las franquicias nacionales en el extranjero. Actualmente hay 15 marcas peruanas de franquicias con un total de 102 locales ubicados en 16 diferentes países, los cuales se distribuyen de la siguiente manera:

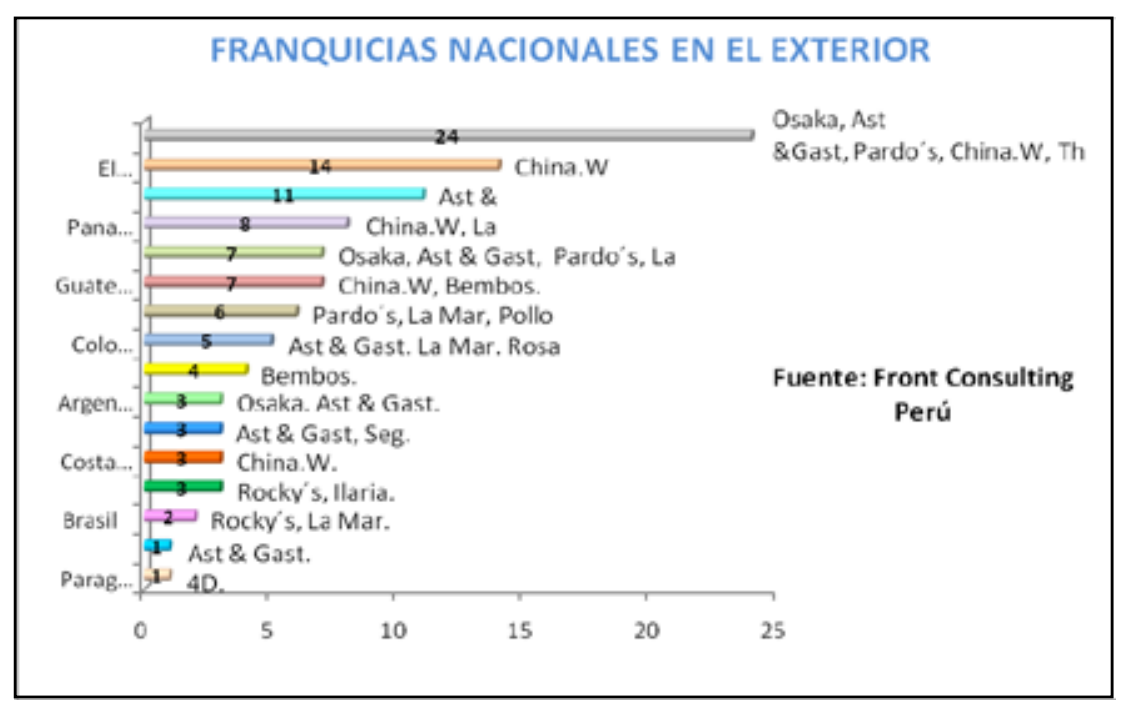




\section{ANTECEDENTES}

El tema de franquicias en el Perú ha sido poco tratado hasta el momento y el poco material de libros se dirige específicamente a detallar datos generales de este negocio, tales como características, los elementos que la componen, ventajas y desventajas, entre otros. Sin embargo, libros o investigaciones con temas más profundos que ayudarían a analizar la conveniencia o no de una legislación específica de franquicias, son muy pocos. Esta realidad amerita una investigación más ardua y profunda, que consiste en la búsqueda de artículos de expertos extranjeros en el tema y que en base a su experiencia y trabajo en el sector, otorguen opiniones reales, así como a buscar libros extranjeros, adquirir guías de franquicias elaboradas en otros países, también leer las pocas tesis relacionadas al tema en el extranjero. La conclusión de todos estos estudios demuestran las grandes bondades que tiene este formato de negocio en muchas áreas de conocimiento, el gran aporte que da en el sector económico; sin embargo, la función jurídica está descuidada, y es justamente esta función la que debe generar un soporte a los nuevos formatos de negocio para generar desarrollo y riqueza en un país que lo necesita.

\section{MARCO HISTÓRICO}

Actualmente el formato de franquicias es utilizada por el sector empresarial como un sistema de comercialización de bienes y servicios; sin embargo, históricamente las franquicias nacieron como un medio de exclusividad de zona.

1. En la EDAD MEDIA, un soberano otorgaba o concedía un privilegio a sus súbditos, quienes en virtud del mismo podían realizar actividades tales como la pesca y la caza, dichas actividades les eran reservadas a determinadas zonas del reino. ${ }^{2}$

2. En la EDAD MODERNA, el primer antecedente de franquicia se da en Estados Unidos, con el otorgamiento a particulares por vía legislativa de la explotación de algunos servicios públicos, como fue el caso de los ferrocarriles y los bancos. De esta manera, las franquicias realizadas por el gobierno constituyeron un medio para desarrollar la prestación de servicios de una manera rápida y sin utilización de dinero o fondos públicos. ${ }^{3}$ Por otro lado, las personas a quienes les otorgaban estos derechos, estaban supeditadas a estar controladas y vigiladas administrativamente por el Estado sobre los servicios que realizaban; sin embargo, el derecho de exclusividad sobre explotación de tales servicios, les daba el beneficio de lograr significativas ganancias.

3. En la EDAD CONTEMPORÁNEA, la historia de las franquicias continúa con grandes ejemplos en Estados Unidos, pues las necesidades de expansión de este país después de la guerra civil, llevan a los empresarios a buscar la colaboración de los comercian- tes del Sur y del Oeste. Bajo estas circunstancias, reaparece el término franquicia, pero esta vez ya contiene la esencia que lo caracterizará hasta nuestros días, la colaboración entre empresarios independientes para la obtención de un fin común. Es en esta etapa donde la franquicia sale a relucir de la mano de empresas conocidas hoy en día como grandes cadenas.

Bajo este contexto, en 1850, Estados Unidos de Norteamérica, es el país en donde se considera que el sistema de franquicias comenzó de la mano de la empresa de máquinas de coser Singer (Singer Sewing Machine), en donde su dueño, Isacc Singer, estableció un sistema de licencias para que comerciantes de todo el mundo puedan vender sus máquinas de coser. La historia de esta empresa inicia debido a que durante la década de 1850 a 1860, le resultaba muy alto los costos laborales de contratar vendedores directos para sus máquinas de coser, es entonces que deciden cambiar su estructura básica de funcionamiento, que consistía en establecer una red de concesionarios / vendedores a quienes se les cobraba una participación por el derecho a distribuir sus máquinas de coser en territorios, esto ayudó a Singer a convertirse en una de las marcas más reconocidas en el territorio norteamericano.

En 1899, mediante la utilización de este sistema, la empresa Coca-Cola se convirtió en la primera embotelladora 
del mundo. Para esa época, Coca-Cola operaba directamente sus fuentes de soda donde expendían su producto. Sin embargo, algunos inversionistas lograron convencer a la firma para que les otorgara el derecho a proveerse, por parte de Coca-Cola, del concentrado necesario para embotellar la bebida en las instalaciones del franquiciado, quien se encargaría de distribuirla a nivel regional. El franquiciado, absorbía así el $100 \%$ del costo de instalación y se encargaba de su manejo, a cambio de recibir el concentrado necesario para el producto y el apoyo publicitario centralizado. ${ }^{4}$ Conforme crecía la demanda del producto, los primeros franquiciados de Coca-Cola vendieron a su vez franquicias a otros nuevos franquiciados, convirtiéndose en lo que hoy se conoce como Master Franquicias.

En 1921, la empresa Hertz Rent a Car resolvió ampliar su red de distribución a través de concesiones similares a las franquicias, siendo hoy, entre otras, líder mundial en el servicio de arrendamiento de vehículos, con más de 370 franquicias otorgadas y 1076 puntos de operación de servicios.

Posteriormente, en 1898, General Motors también adoptó la franquicia como estrategia para expandir su red de distribuidores, ya que no contaba con los recursos para abrir puntos de comercialización propios, viéndose en la necesidad de otorgar concesiones, sistema exitosamente utilizado en la industria automotriz de hoy en día. Sin embargo marca una diferencia en el año de 1929, cuando esta empresa recurre a un contrato que favorece el asociacionismo entre la central y sus distribuidores, fomentando la colaboración entre las partes pero manteniendo en niveles razonables su independencia. En ese año, General Motors perfeccionó su política inicial y diseñó un contrato que asociaba con más libertad a revendedores, constituyendo así el primer modelo de contrato de franquicia en los Estados Unidos. ${ }^{5}$

Mientras que paralelamente en Francia, la franquicia nació en el norte, teniendo como precursor a la fábrica de lanas La Lainiere de Roubaix, quienes desde 1929 practicaban el modelo de franquicia, cuando todavía nada se había escrito sobre el tema. Esta empresa trataba de asegurar las ventas comerciales para la producción de una nueva planta y para tal efecto, buscó asociarse con un número de detallistas independientes ligados por un contrato que les garantizaba la exclusividad de la marca en un sector geográfico determinado. Si bien la fórmula no estaba aún muy sistematizada, era cuestión de sólo esperar hasta 1970 para observar una verdadera eclosión de la franquicia. $^{6}$

A mediados de 1930 , surge en el mercado norteamericano las franquicias de los hoteles y los restaurantes Howard Johnson cuyo caso merece ser comentado. Ya que surge luego de la gran depresión que sufrió el dinamismo empresarial que se vivía en los Estados Unidos. Esta conocida cadena se había iniciado en 1925 como un negocio de helados con un capital inicial de US\$500, obtenido de préstamos de terceros. El negocio evolucionó hasta llegar a convertirse en una cadena de restaurantes exitosos, la característica que la diferenciaba era de tener un techo naranja brillante. El señor Johnson debido a la carencia de los recursos económicos necesarios para inaugurar nuevos restaurantes, utilizó el formato de franquicia como sistema de expansión. Es así que celebró un acuerdo de franquicias, con un compañero de universidad, mediante el cual se comprometió, por un lado a venderle helado y otros productos relacionados con el negocio, y por otro a ayudarle con el diseño, instalación y supervisión del restaurante.

Algo coincidente en esta franquicia, fue que los franquiciados no tenían experiencia previa en el negocio de los restaurantes. Sin embargo, a través de las franquicias, sus dueños obtenían los beneficios que le otorgaban el franquiciante, tales como la experiencia y la oportunidad de beneficiarse de las ganancias de un concepto probado. A cambio Howard Johnson obtuvo ganancias de los productos que vendió a sus franquiciados y una mayor expansión de su marca.

Finalmente, en 1954, ocurrió el hecho que dio verdadero auge a la franquicia, su adopción por parte de la empresa Mc Donald's, cuyo caso de éxito es conocido a nivel mundial. 
Luego, vendrían más casos de empresas de éxito gracias a que adoptaron el formato de franquicias como opción de crecimiento. Sin embargo, las historias de las empresas mencionadas son consideradas las pioneras en el tema.

\section{EVOLUCIÓN DE LA FRANQUICIA A NIVEL NACIONAL}

La evolución de las franquicias se distingue en cuatro etapas de acuerdo a la maduración que vaya obteniendo el sector en su país. Siendo así, se hace necesario saber las características de estas cuatro etapas por las que todo mercado nacional de franquicias tiene que pasar en su respectivo país y así entender mejor la situación actual del mercado de franquicias en el Perú y sus antecedentes.

\section{Primera etapa}

Se caracteriza por el ingreso de reconocidas marcas de franquicias extranjeras al mercado nacional. Generalmente estas marcas extranjeras son adquiridas como franquicia por grandes grupos empresariales locales y con poca intención de subfranquiciar los formatos de franquicia que desarrollan a franquiciados individuales. En su mayoría las franquicias extranjeras en esta primera etapa pertenecen al sector gastronómico, y con el transcurrir de los años son consideradas como las pioneras.

En el Perú, esta primera etapa se da en los años ochenta con el ingreso al mercado nacional de franquicias extranjeras. Exac- tamente en 1981 con el ingreso de KFC, y en 1983 con Mc Donald's. Estas marcas foráneas hacen su entrada al país de la mano del grupo empresarial Delosi, grupo local franquiciado que hasta la actualidad mantiene la Master Franquicia de estas marcas y que además no otorga subfranquicias a franquiciados individuales. Luego de estas dos primeras franquicias, Delosi seguiría dedicada a la operación de franquicias como Pizza Hut, Starbucks, Chilis, Burger King, Pinkberry; entre otras marcas en el Perú.

Si bien en el Perú surgen las franquicias con la llegada de KFC y ésta fue aceptada de inmediato por el público, lo que todo indicaba ser un "boom" para el sector se vio obstaculizada por los ataques terroristas que sufrió Pizza Hut, debido a la bomba que pusieron en su local de Miraflores y de cómo este incidente los dejó exentos de cumplir el contrato que los obligaba a seguir inaugurando dos o tres locales cada año, ahuyentando así el posible ingreso de otras marcas extranjeras. ${ }^{7}$ Tristemente, la expansión del Formato de Franquicias se vio paralizada en los años 80 a consecuencia del terrorismo y la difícil coyuntura económica; mientras que en otros países como Colombia y Venezuela, sí evolucionó favorablemente.

\section{Segunda etapa}

Se caracteriza por los primeros indicios de franquiciabilidad de conceptos locales y una diversificación tímida de rubros en el sector. Es decir, un pequeño número de empresas nacionales empieza a creer en el formato de franquicias como opción para hacer crecer sus negocios, ello en base al éxito que observaban tener las empresas extranjeras que entraron bajo este formato en la primera etapa (KFC, Mc' Donalds, Burguer King, etc). De esta manera, empresas peruanas apuestan por este formato, aún con cierta desconfianza, pero se aventuran e inician la conversión de su negocio al formato de franquicia. En esta etapa se observa aún mayor participación del sector gastronómico en el mercado, sin embargo ya se logra vislumbrar alguna franquicia de otro rubro.

En el Perú, la segunda etapa se vive en los años noventa, coincide con un periodo de estabilización y apertura económica, luego de una etapa de convulsión política, esta segunda etapa permitía el regreso de franquicias extranjeras y la aparición de conceptos peruanos que parten de la iniciativa privada, algunos de ellos hoy convertidas en grandes cadenas exitosas gastronómicas como Pardo'sChicken, Mediterráneo Chicken, Bembos, entre otros.

\section{Tercera etapa}

Es la etapa denominada "Boom" o popularización de las franquicias, en donde una gran cantidad de negocios locales adopta el formato, y entran mayor número de franquicias extranjeras. El desarrollo de franquicias locales suele llegar a niveles del $60 \%$ del total de las franquicias. También esta etapa se caracteriza por la exportación de franquicias nacio- 
nales. Además, los grupos empresariales que tenían la Master Franquicia, comienzan a subfranquiciar los conceptos que originalmente operaban sólo ellos.En esta etapa se profundiza el elemento educativo, se inicia la divulgación del tema mediante cursos de pregrado y postgrado. Por otro lado, como parte de la importancia que va adquiriendo el sector, surge la fundación de instituciones de apoyo como las Cámaras de Franquicias e Instituciones del Estado dedicados a incentivar el sector franquicias.

Asimismo, debido a que es una etapa de crecimiento que vive el sector en el país, van a aparecer franquicias serias y transparentes, como también van a surgir las otras llamadas "Franquicias chatarras", es decir, aquellas que se hacen llamar franquicia pero puede resultar el peor fiasco ya que no cumplen con muchos de los requisitos que involucra ser franquicia; surgiendo la oferta profesional versus la oferta chatarra en esta etapa.

En el Perú, se vive hoy en día esta tercera etapa, que inicia en el año 2004, marcada con una apuesta masiva de negocios nacionales que se convierten en franquicia, la fundación de la Cámara Peruana de Franquicia
(CPF), mayor divulgación del tema con cursos y exportación de conceptos gastronómicos, así como la aparición de "franquicias chatarras". En la actualidad el desarrollo de franquicias nacionales estima el $40 \%$ del total del mercado nacional de franquicias.

Para una mayor comprensión, se divide el mercado peruano de franquicias según el origen de las marcas franquiciantes, resultando el $40 \%$ de origen nacional y $60 \%$ de origen extranjero, porcentaje que justifica el motivo por el que Perú se encuentra en una tercera etapa de la evolución de sus franquicias.

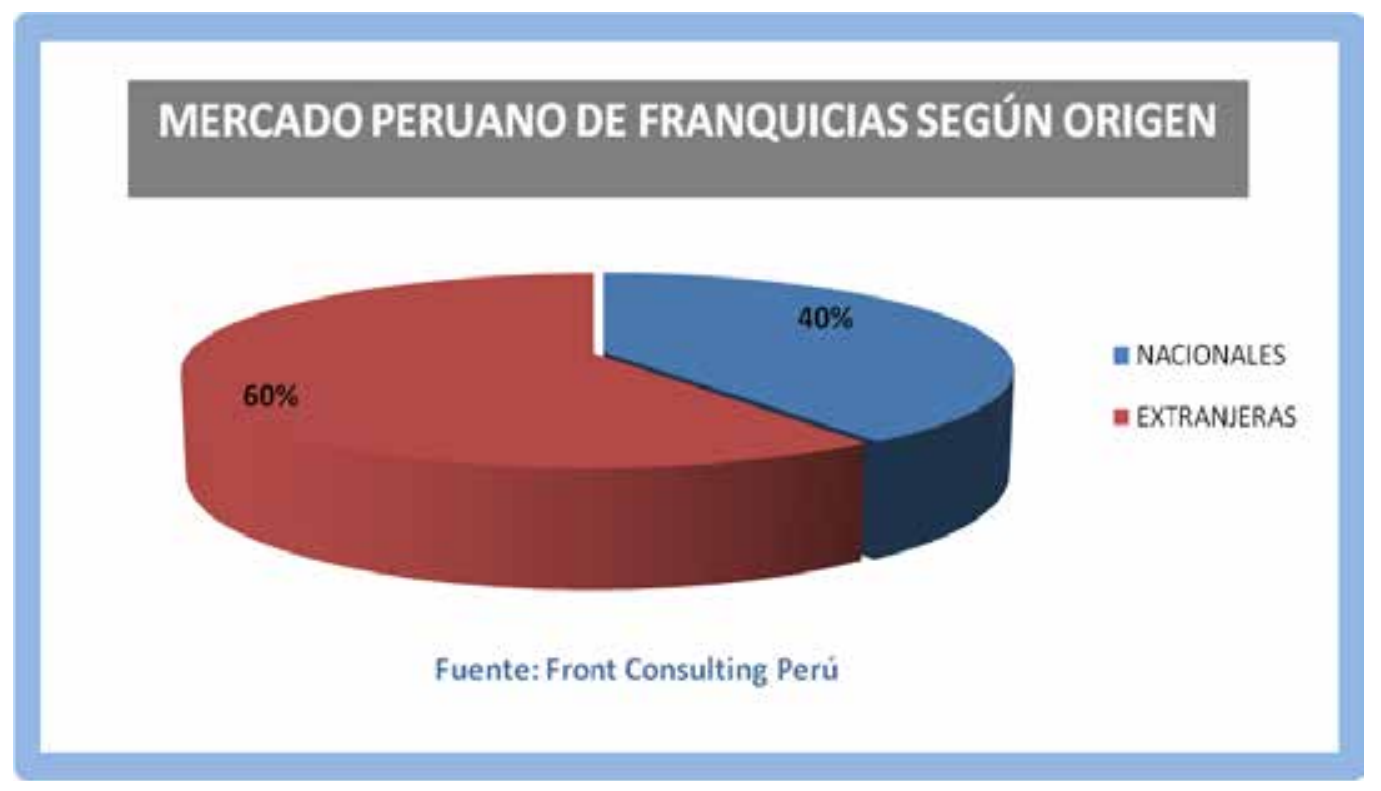

\section{Cuarta etapa}

Esta etapa se caracteriza por la consolidación y profesionalismo del sector así como por una depuración de los protagonistas. Las franquicias nacionales predominan en el mercado, desplazando a un mínimo a las franquicias extranjeras operativas en el país. También se caracteriza por debates de la existencia de una normativa especializada y mayor exportación de franquicias locales a otros mercados.

Países en Latinoamérica como Brasil, México, Argentina y Venezuela ya se encuentran en esta etapa.Actualmente el mercado de franquicias en el Perú se encuentra en su tercera etapa y dependerá de la rapidez de su desarrollo integral, para que pase a una cuarta etapa.

Según el Portal de la FIAF, entre los países que se encuentran en la tercera etapa, lidera Colombia con el $55 \%$ seguido por Perú con $40 \%$ de marcas nacionales. Países como Ecuador, Guatemala y Uruguay se encuentran aún en la segunda etapa de evolución. 


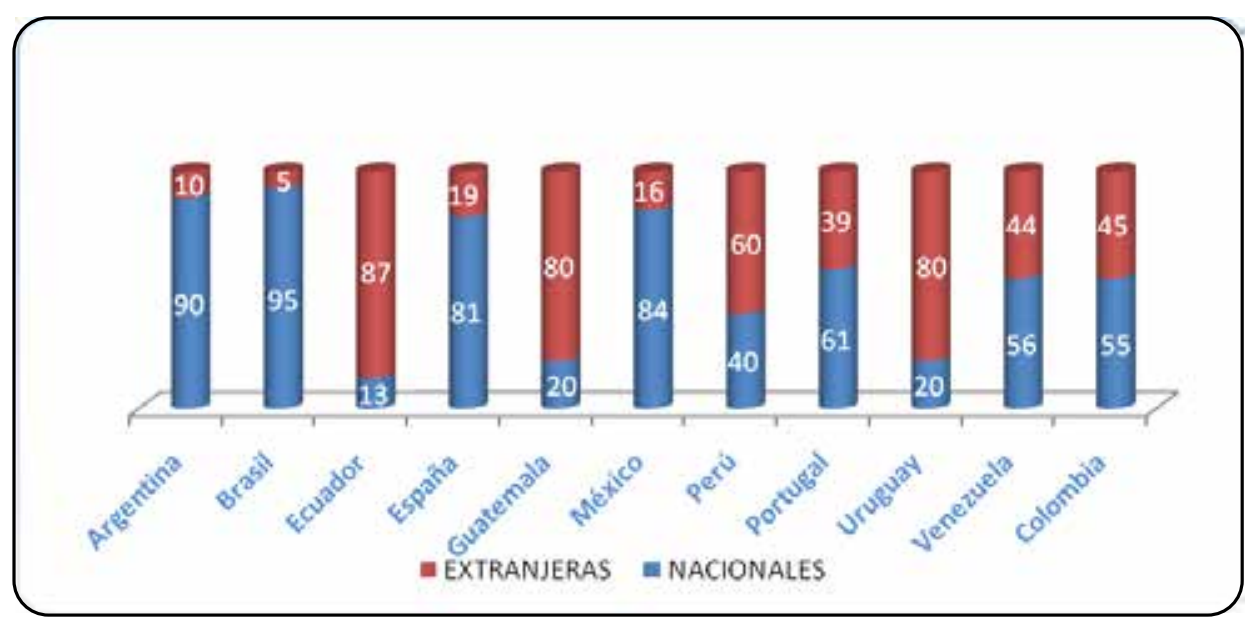

Fuente: Portal de la FIAF

\section{ELEMENTOS DE LA FRANQUICIA}

\section{Franquicia}

Es un formato de negocio dirigido a la comercialización de productos y/o servicios, basado en la colaboración de dos personas jurídica y financieramente independientes, en donde una persona natural o jurídica (franquiciante) cede a otra (franquiciado) a cambio de contraprestaciones económicas, el derecho de usar la marca, knowhow, método operacional propio de su concepto de negocio para que sea explotado en un nuevo punto de venta, por un tiempo determinado y bajo una asistencia técnica permanente con la finalidad de salvaguardar un servicio homogéneo y repetir el éxito del franquiciante.

Convertirse en franquicia implica que la empresa sea objeto de transformación en todos sus aspectos (imagen, financiera, administrativa, comercial, entre otros) de manera que todos sus procesos guarden un orden y transparencia, para cumplir con la finalidad de este formato de negocio, ser "clonada" en otros puntos de venta.

\section{Franquiciante}

Es la persona natural o jurídica, dueña de una marca, de un knowhow y un método operacional que, conjuntamente, han llevado al éxito su negocio. Ante tal éxito, convierte su negocio a franquicia para ofrecerlo bajo este formato a un inversionista a cambio de contraprestaciones económicas. Asimismo, brindará una asistencia técnica permanente para que los elementos cedidos por la franquicia funcionen logrando el éxito proyectado.

\section{Franquiciado}

Es el inversionista, persona natural o jurídica que adquiere los derechos de la marca, el knowhow y el método operacional del franquiciante, a cambio de las contraprestaciones económicas pre-establecidas. Es el inversionista que invierte dinero y su trabajo para iniciar una actividad comercial de manera propia e independiente. Esta persona es la que va gestionar de manera directa la explotación de la franquicia en un nuevo punto de venta y para lograr la proyección de éxito deseada, tendrá como derecho la asistencia técnica continua del franquiciante.

\section{Marca}

La marca al ser un signo distintivo que sirve para diferenciar productos y servicios en el mercado, se convierte en el elemento esencial de la franquicia, es juntamente con la insignia y el nombre comercial, la piedra angular del sistema. La imagen de la marca es, en efecto, el cimiento de toda franquicia, es el signo de adhesión para el consumidor a quien se intenta conquistar.

La marca debe ser elegida con minuciosidad, sabiendo que ella debe responder a dos objetivos: debe ser atractiva comercialmente, así como segura jurídicamente; para lo último debe ser registrada en el Instituto Nacional de Propiedad Industrial (INDECOPI).

\section{Know how}

Literalmente significa "saber hacer", es uno de los elementos fundamentales del sistema de franquicia. Se refiere a todo el conjunto de experiencias y procedimientos que han sido adqui- 
ridas por un empresario en la explotación de su negocio y que le han permitido alcanzar un cierto éxito en el sector de actividad de su mercado. ${ }^{8}$

Este conjunto de conocimientos prácticos relativos a la manera de producción, comercialización, gestión y financiamiento de los productos o servicios, tiene un precio, ya que es el resultado de haber experimentado mediante puestas a punto, ensayos, descubrimientos casuales, originalidades, etc. Este es el Saber-Hacer que brinda el franquiciante al franquiciado para que no pague el conocido "derecho de piso".

\section{Asistencia técnica permanente}

Es la asesoría continua que le da el franquiciante al franquiciado. Esta capacitación suele darse antes y después de aperturar el negocio franquiciado. La idea es que la empresa franquiciante nunca debe abandonar al franquiciado, si éste tiene algún problema de cualquier índole: con algún equipo, con la proveeduría, con las cuentas, con los productos, etc., tendrá siempre a quien llamar; a un "hermano mayor" a quien acudir en caso de problemas. Por su parte, el franquiciante también debe velar porque los franquiciados estén realizando los procesos como se debe, evitar las alteraciones, cuidar la imagen, calidad, servicio, atención, etc.

\section{Contraprestaciones}

Son los pagos que el franquiciado está obligado a abonar al franquiciante por el uso de su marca, knowhow y la capacitación permanente que recibirá a lo largo de la vigencia del contrato.

Estas contraprestaciones se dividen típicamente en tres tipos: canon de entrada, regalías comerciales y canon de publicidad.

\section{Manuales de operación}

Es la codificación del knowhow de una forma práctica y didáctica. Son herramientas impresas que sirven para transmitir toda la información que necesita el franquiciado para poder operar el negocio efectivamente. Estos manuales son imprescindibles para la capacitación y una herramienta de consulta permanente cuando aparecen las dudas del día a día cuando se está en plena operación del negocio. Los aspectos que los manuales deben contemplar son: actividades de pre-apertura, operaciones, administración, contabilidad, mercadotecnia, políticas de imagen corporativa, instalaciones y equipamiento, políticas de recursos humanos, utilización de software, manual del empleado. ${ }^{9}$

\section{Circular de oferta de franqui- cia (COF)}

Es un documento de información de la franquicia que el franquiciante otorga al franquiciado interesado. La COF describe los aspectos más relevantes de la franquicia como nombre, descripción del concepto de negocio, antigüedad de la empresa franquiciante, derechos de propiedad intelectual que posee la franquicia, obligación de montos de pago que tiene el franquiciado, tipo de asistencia técnica que se brinda y demás servicios que se ofrecen.

En países como Estados Unidos, en donde se le conoce como Uniform Franchise Offering Circular, debe ser entregado al franquiciado antes de la firma del contrato; asimismo en países como Venezuela, Brasil y México ponen un plazo mínimo antes de la firma del contrato para que sea entregado al franquiciado, ello para cumplir con el derecho a la información que éste debe tener.

En el Perú no hay una obligación proveniente de una ley, de otorgar la COF previamente a la firma de un contrato. Sin embargo, esto lo hacen como costumbre algunas franquicias cuando están asesorados por una consultora especializada que los oriente sobre lo importante de esto, pero ¿Qué pasa con aquellas franquicias que no tienen una asesoría?

\section{Contrato de franquicia}

Es el documento por el cual el franquiciante establece la voluntad de ceder su franquicia a un franquiciado, estableciendo los derechos y obligaciones de ambas partes, así como todas las cláusulas necesarias para el buen funcionamiento del establecimiento durante la vigencia del contrato y a la terminación de este.

\section{Territorio}

El territorio es la zona de actuación a favor del franquiciado, 
en la que éste desarrolla su negocio, en una ubicación específica cuya determinación puede ocasionar el éxito de la operación de la franquicia. ${ }^{10}$

En efecto, el territorio en el que se explotará la franquicia es uno de los elementos que debe quedar bien definido en un contrato de franquicia, para evitar posteriores conflictos. Lo normal en este tipo de negocios es que la puesta a disposición de una marca se limita a un territorio concreto, conocido comúnmente, como exclusividad territorial, que se le da al franquiciado para operar.

\section{Tropicalización}

Son los pequeños cambios o ajustes a los que se somete un producto o servicio con el propósito de adaptarlo al mercado objetivo que se desea captar. Estos ajustes pueden ir desde cambio del nombre en el idioma del país receptor hasta el tipo de ingredientes que interviene en la preparación del producto.

Un ejemplo en Perú mismo sería la venta de los pollos de KFC, por ejemplo en "Frutales" se venden con papas fritas; pero si se va al KFC del "Centro Comercial Cánepa" se vende acompañado de arroz verde. Esto se explica porque el público al que se dirigen es diferente. En Frutales, la gente que asiste es por comer un antojo, la gente que visita el centro comercial Cánepa quiere saciarse porque está exhausto de su trabajo o compras; los otros fastfood de este mismo centro comercial dan cantidad, por lo que KFC tropicaliza su producto al dar este complemento de arroz que no es característico de esta marca.

\section{Situación de las fRANQuicias en el Perú}

En esta última década se han advertido logros que se reflejan en el crecimiento nacional del sector, como son la creación de nuevos conceptos de franquicias diferentes al sector gastronomía, exportación de franquicias nacionales, creación de nuevos empleos directos e indirectos. Además de esto, está la promoción para la formalización a la que se tienen que someter las empresas, que es convertirse al formato de franquicia mediante una asesoría profesional, ya que parte del desarrollo del sector implica ser totalmente forma- les. Si bien el número de franquicias ha aumentado considerablemente, se hace necesario un mayor esfuerzo de parte de los actores en la divulgación del concepto; pues cada vez son más los empresarios, estudiantes y emprendedores en general que buscan saber acerca de la franquicia y sus beneficios. Por otro lado, el contexto actual se presenta con la inexistencia de un marco regulatorio para los sistemas de franquicias en el Perú, situación comprensible en principio ya que obedece a un mercado aún incipiente, en cuanto a número de personas que apuestan por este formato, así como transacciones que no ameritaban una regulación y eso es un estadio normal en la evolución observada en la mayoría de países, los cuales suelen regular a partir de una necesidad generada por el mismo mercado y no impuesta antes de ésta.

En el Perú, este sistema de negocios brinda 20000 puestos de trabajo. México brinda 680000 puestos de trabajo, por lo que es una gran diferencia y suficiente motivo para seguir impulsando el sector, ya que con esto se pueden generar muchos puestos de trabajo.

\begin{tabular}{|l|l|l|l|l|l|l|}
\hline País & $\begin{array}{l}\text { Narcas } \\
\text { Marionales }\end{array}$ & $\begin{array}{l}\text { Extranjeras } \\
\%\end{array}$ & $\begin{array}{l}\text { Facturación } \\
\text { Millones } \\
\text { (USB) }\end{array}$ & Unidades & Personal \\
\hline Argentina & 500 & $89 \%$ & $11 \%$ & & 20000 & 185000 \\
\hline Brasil & 1855 & $93 \%$ & $7 \%$ & 47500 & 86365 & 777000 \\
\hline Colombia & 400 & $55 \%$ & $45 \%$ & 4200 & 6900 & 30000 \\
\hline Ecuador & 203 & $13 \%$ & $87 \%$ & 974 & 1350 & 14521 \\
\hline España & 934 & $81 \%$ & $19 \%$ & 35382 & 56444 & 231603 \\
\hline Guatemala & 300 & $20 \%$ & $80 \%$ & & 10575 & 106000 \\
\hline México & 954 & $84 \%$ & $16 \%$ & & 70000 & 680000 \\
\hline Perú & 268 & $40 \%$ & $60 \%$ & 600 & 1800 & 20000 \\
\hline Portugal & 570 & $59 \%$ & $41 \%$ & 7854 & 12016 & 73143 \\
\hline Uruguay & 280 & $20 \%$ & $80 \%$ & & & 25000 \\
\hline Venezuela & 400 & $55 \%$ & $45 \%$ & & 9000 & 90000 \\
\hline
\end{tabular}

Fuente: Portal de la FIAF

10 Salazar, Sergio. 2007: 24. 
Es innegable que una economía de mercado necesita de una estabilidad económica y jurídica; la primera dependerá en cierta forma del gobierno de turno y las políticas que se tomen (lo cual no generan siempre un inconveniente para los sistemas de franquicias; al contrario, a veces suele ser favorable). Sin embargo el aspecto jurídico si es algo que requiere la atención del legislador, más aún cuando la propuesta jurídica es discutida por doctrinarios, juristas postulantes, pragmáticos, empresarios, franquiciantes, franquiciados y consumidores. Países como México, el cual ya había incorporado años atrás ciertos lineamientos sobre las Franquicias en su Ley de Propiedad Industrial, hoy en día se encuentran ante la necesidad de una ley propiamente de franquicias, ya que si bien en su momento estos artículos en su Ley de Propiedad Industrial ayudaron a un mayor impulso del sector de franquicias en el país, con ello aumentaron también las cifras de demandas sobre las mismas. Un caso similar ocurre en Argentina, que al igual que en Perú, no tiene normatividad alguna sobre franquicias, pues el sistema se apoya en un sinnúmero de normativas legales; en este país el sector está aún más desarrollado, por lo que ya se logran visualizar conflictos no regulados en el contrato, lo que genera inseguridad jurídica en las partes y todo un problema empresarial por un vacío legal. De esto se desprende, por lógica, que si pasamos de un movimiento conservador de franquicias a un boom de las mismas, las cifras de conflictos crecen. Ante esto, más vale estar a la vanguardia, sin embargo, ¿cómo?, surgen muchas interrogantes, será que ¿la creación de una Ley Marco podría otorgar un crecimiento seguro y robustecedor del sector?, o quizá ¿esto paralizaría el crecimiento del sector?; o a lo mejor, ise deba esperar a que exista una gran demanda de conflictos para recién preocuparse por una Ley? Por otro lado, me pregunto ¿Acaso la triada Justicia, Derecho y Ley no son de por sí dinámicas, mas no estáticas ante la transformación de la sociedad?, ¿Es que los acontecimientos en los países hermanos deben servir sólo para criticar u observar?, no era que ¿las experiencias de otros deben servir de augurio para el futuro? Se espera despejar estas dudas con el desarrollo del presente trabajo.

El dinamismo del sector en nuestro país es innegable, pero es justamente dicho dinamismo el que podría provocar que la forma con la que se ha estado manejando el tema, no sea suficiente en los próximos años.

Ante este contexto, se puede observar:

1. Para empezar, la legislación actual no cuenta con una definición clara sobre lo que es y lo que no es una franquicia, y mucho menos define los derechos y obligaciones que adquieren cada una de las partes que firman un contrato, además de los elementos básicos de la relación que no debe dejar de regularse.

2. Debido al dinamismo propio del sector, aparecen si- tuaciones de conflicto que no cuentan con casuística o jurisprudencia de referencia, resolviéndose mediante transacciones que dejan inconformes a las partes intervinientes, por lo que esta situación amerita pensar que se necesita contar con parámetros claros para la resolución de estos conflictos. Asimismo a futuro, se debe evitar, las malas interpretaciones o aplicaciones de las normas existentes para la resolución de conflictos en franquicias, ya que en otros países se suelen emitir fallos que no tienen en cuenta la naturaleza jurídica de la franquicia, generando toda una cadena de apelaciones de nunca acabar. Incluso, existen casos de imputación de responsabilidad solidaria entre franquiciante y franquiciado por erradas interpretaciones de autoridades que atentan contra el sentido y ventajas del sistema de franquicias, lo que ameritaría una mayor difusión del concepto en autoridades jurisdiccionales.

3. Otro aspecto, es la necesidad de formalizar y profesionalizar el sector, debido a la aparición constante de empresas que se hacen llamar franquicias y en realidad ofrecen oportunidades de inversión que conllevan al fracaso y al descrédito del sector, afectando la imagen de aquellas empresas que si pasaron por un proceso previo de análisis, consultoría especializada y preparación antes de ofertarse como franquicias. Estas empresas o seudofran- 
quicias son conocidas técnicamente como "Franquicias Chatarras" o coloquialmente como "Franquicias chicha" o "franchichas".

4. La inexistencia de una regulación sobre la Circular de Oferta de Franquicias (COF) que debe brindar el franquiciante al mercado de sus potenciales franquiciados. Este es un aspecto muy importante que forma parte de un proceso de formalización del sector. Los países que cuentan con regulación, hacen mayor énfasis a regular este tema de información previa de las condiciones de la empresa franquiciante, por considerar esta etapa como vital en la futura relación entre el franquiciante y el interesado en adquirir la franquicia. De esta manera, buscan tutelar y salvaguardar la inversión del franquiciado mediante la exigencia de condiciones mínimas de esta oferta y evitando por ejemplo, compras por impulso o recibir información incompleta acerca de los servicios y asistencia a recibir a cambio de las contraprestaciones económicas de este modelo de negocios. Por citar un ejemplo, México legisló como obligatoria la entrega de una Circular de Oferta de Franquicia, qué elementos de información debe contener esta COF, condiciones, e incluso el plazo previo en que este documento deberá ser presentado al futuro franquiciado. Esta regulación trajo como efecto inmediato en el mercado, formalización y mayor dinamismo del sector reflejado en un incremen- to de su participación en el PBI.

5. Por último, no existe un registro formal de las empresas franquiciantes ni de sus contratos. Existe un registro de franquicias voluntario o facultativo, ante INDECOPI en el que figuran no más de 20 franquicias extranjeras registradas. Esta situación genera en la actualidad, dos imprevistos:

a. Este registro no tiene efectos de información frente a terceros, genera inseguridad a los interesados en una franquicia al no saber si es una franquicia formal o no.

b. No permite un control estadístico acerca de la evolución del sector franquicias, ni saber el porcentaje de participación de marcas nacionales $y$ extranjeras.

Es sabido por todos los países que tienen legislación, que la franquicia bien concebida genera un círculo virtuoso en el cual se generan puestos de trabajo, se capacita a la gente y se convierten en una oportunidad para personas que tal vez no encuentran una salida laboral.

\section{LegISLACIÓN NACIONAL}

El aspecto legal nacional suele sonar para muchos como algo tedioso y aburrido; sin embargo, éste resulta ser un aspecto muy importante para el desarrollo de un formato de negocio como este, más aún resulta interesante para las personas que estamos inmersos en el área del Derecho.

Jurídicamente la institucionalidad de las franquicias ha con- tado con mayores detractores, quizás por el estatismo y formalidad que arropan la evolución del Derecho en comparación con las innovaciones comerciales, no teniendo en cuenta que la legislación debe ir acorde a la evolución de la sociedad.

Actualmente en el Perú no existe una normativa que regule a las franquicias, pues el Perú tiene un sistema multirregulatorio. Ante esto, es tarea del gobierno establecer una reglamentación que permita el desarrollo del sector a través del establecimiento de leyes promotoras y regulatorias.

El sistema multirregulatorio refiere a que son varias las normas - leyes a las que se tiene que acudir para que en conjunto otorguen un respaldo y soporte legal a estos formatos de negocio. Esto es muy importante, debido a que el fin último en el sector empresarial es el inicio de operaciones comerciales con las implicaciones jurídicaseconómicas que ello implica. Caso opuesto es el sistema autoregulatorio, mediante el cual se crea una legislación especial para las franquicias, como son los países de Brasil, México, España.

Existen ciertas leyes en el país que actualmente enmarcan la operatividad de las franquicias de acuerdo a las normas nacionales vigentes, éstas son la Consititución Política del Perú, mediante sus artículos del capítulo de Régimen Económico, el Código Civil respecto a los artículos de contratos, obligaciones y acto jurídico, la Decisión 291 del Acuerdo de Cartagena, respecto al tratamiento del capital extranjero y sobre marcas, 
patentes y regalías, el Decreto Legislativo 807, respecto a las facultades que asume INDECOPI de acuerdo a lo solicitado por el Acuerdo de Cartagena, el Decreto Legislativo 662, respecto a la estabilidad jurídica para la inversión extranjera y la Ley de Propiedad Industrial, respecto a las marcas.

Sin embargo, la existencia de estas normas no es suficiente para otorgar una plena seguridad jurídica a los contratantes y menos aún promocionar este modelo como una opción para expandir un negocio. Además que estos cuerpos legales desarrollan el tema de las inversiones extranjeras en el Perú, pero no detallan aspectos de la operatividad del Sistema de Franquicias en sí. Al no existir un parámetro legal y/o ético que regule específicamente a las franquicias, estamos expuestos a que con el crecimiento del sector también se acrecienten el número de conflictos y estas normas básicas y generales no sean suficientes para ciertos supuestos.
EXISTENCIA DE CONFLICTOS EN EL SECTOR

\section{Encuestas}

Años atrás teníamos un mercado aún incipiente, no existía una demanda considerable de empresas interesadas en franquiciar sus conceptos de negocio, eran pocas las empresas que creían en este formato ya que lo veían con mucha desconfianza. Ante aquel contexto, es lógico que no se visualizara la necesidad de normar sobre el tema, lo cual es normal en todos los países, pues se tenía que esperar un mayor desarrollo del sector para pasar a una etapa de regulación. No obstante, hoy la situación ha cambiado. Hoy podemos observar que ya no hablamos de 10 empresas peruanas, sino de 100; ya no hablamos de 100 empresas extranjeras norteamericanas, hablamos de alrededor de 300 de distintos países de origen; ya no hablamos de franquicias sólo gastronómicas, sino también de otros servicios. Es innegable que el mercado ha cambiado.
La lógica nos lleva a pensar que de crecer un mercado, también crecen los conflictos que puedan suscitarse entre ellos, es lógico que si se pasa de un desarrollo conservador a un "boom" de las mismas, de manera directamente proporcional crecerán las incertidumbres y problemas.

Para constatar que efectivamente al haber pasado de un mercado incipiente a un mercado con pleno desarrollo del sector y que con ello, los conflictos jurídicos entre las partes también se están haciendo presente, se ha acudido a una investigación de campo, las conocidas encuestas.

En primer lugar se hace necesaria una estadística global. Siendo así, el total de marcas de franquicias nacionales y extranjeras que operaban hasta el 2012 en nuestro país ascendían a la cifra de 268 , lo que constituye el universo de empresas estudiadas, divididas según su origen. Las estadísticas del 2009 de PROMPERÚ, no señalan el total de franquicias operantes. ${ }^{11}$

\begin{tabular}{|l||l|l|}
\hline ORIGEN & NRO. FRANQUICIAS & PORCENTAJE \\
\hline \hline NACIONALES & 106 & $40 \%$ \\
\hline EXTRANJERAS & 162 & $60 \%$ \\
\hline TOTAL & 268 & $100 \%$ \\
\hline Fuente: Front Consulting Perú \\
\hline
\end{tabular}

\section{Encuestas a franquicias nacionales}

Se tomó como población al $10 \%$ del total de franquicias nacionales, que en conclusión respondieron en su totalidad haber tenido algún conflicto de orden jurídico con algún franquiciado; $y$ en su totalidad confirmaron que una Ley especial de franquicias le daría mayor seguridad jurídica para la celebración de sus contratos comerciales.

En el 2009, PROMPERÚ señala que la gastronomía tenía una participación del $64 \%$ del mercado nacional de franquicias. Por lo que se puede observar que si bien han crecido el número de otros sectores, la participación gastronómica también crece con ello.

11 Portafolio de Franquicias Internacionales: PROMPERÚ 


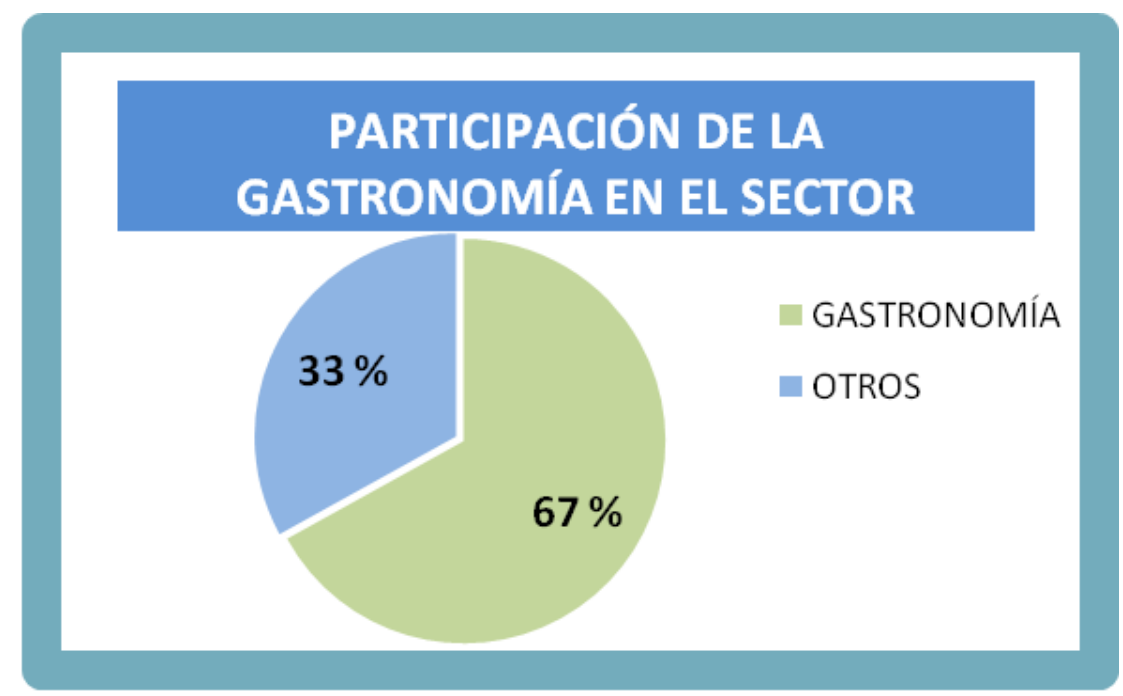

Fuente: Front Consulting Perú

\section{Encuestas a franquicias extranjeras}

Se tomó como muestra al $10 \%$ de esta población, que en conclusión creen que una legislación especial de franquicias en el Perú lo haría sentir más se- guro para buscar franquiciados y celebrar contratos en este país.

En el siguiente cuadro, se observa el número de franquicias extranjeras que operan en la actualidad en el país, clasificados por países de origen. Observamos que Estados Unidos lidera el mercado de franquicias extranjeras con 76 marcas, seguido por España con 16 marcas y en tercer lugar 15 marcas de origen argentino.

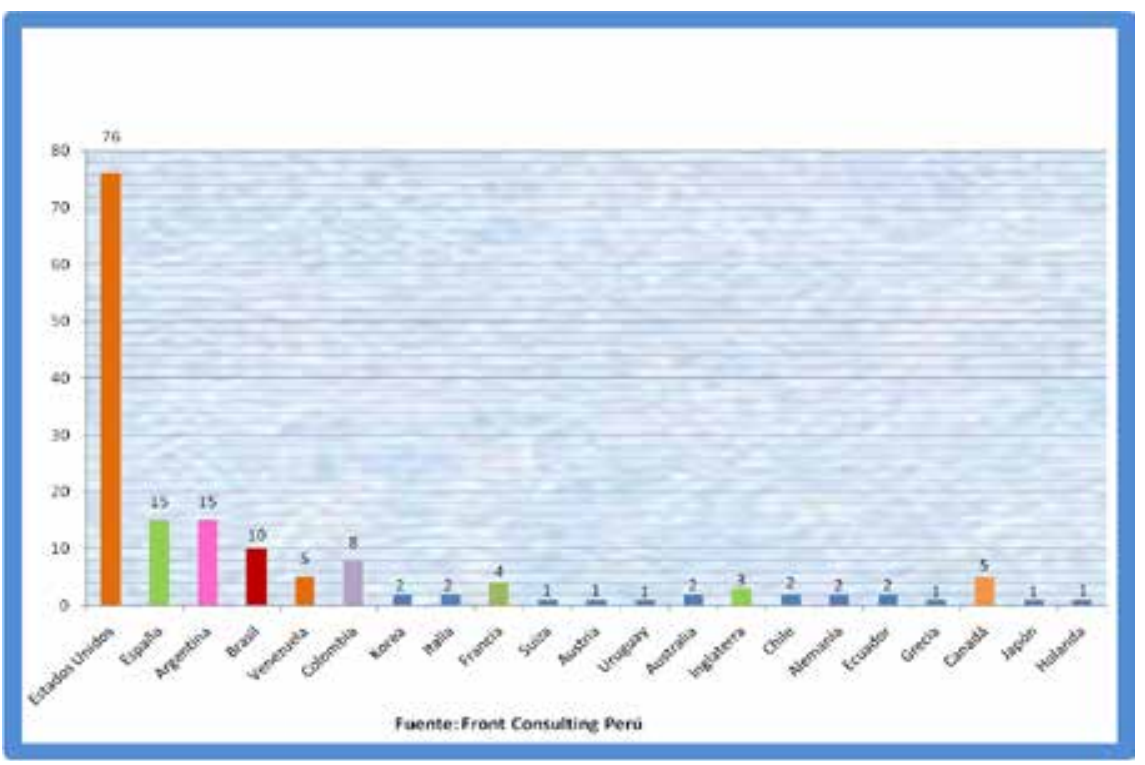

\section{Testimonios}

Las preguntas de las encuestas suelen ser contestadas con mucho recelo, pues a los dueños o representantes de franquicias, les es muy difícil hablar de estos temas por motivos de confidencialidad. Sin embargo, para reforzar la hipótesis planteada, se logró entrevistar a dos personas que relataron con mayor detalle los conflictos a los que se habían enfrentado.

Uno de los casos, fue que el franquiciante vendió un gran porcentaje de sus derechos so- bre la marca, originando todo un caos entre el nuevo franquiciante y los 10 franquiciados de la cadena de franquicia de esta Marca X, por motivo de confidencialidad. El nuevo franquiciante no realizaba la publicidad para toda la cadena, entonces los franquiciados empezaron a 
realizar sus publicidades individualmente, lo que terminó por devaluar la marca al generar confusión en los clientes. En medio de conflictos, todos los franquiciados culminaron el contrato, y sólo quedo un punto de venta, el del franquiciante.

Otro caso, fue que a un franquiciado le vendieron una "franquicia" cuando en verdad era una "franchicha" es decir, no le dieron manuales de operación, no tenía una asistencia técnica permanente, sólo le habían dado el derecho a usar la marca y le habían cobrado como franquicia.

\section{Entrevistas a especialistas}

Las diferentes entrevistas realizadas a especialistas extranjeros y nacionales sobre el tema, llevaron a la conclusión de que debe haber una legislación especial en franquicias, que sea marco, sofisticada y no recargada, con la finalidad que otorguen mayor seguridad jurídica a los franquiciantes como franquiciados para así asegurar más allá de un crecimiento del sector, que éste sea sostenido y profesional.

\section{LEGISLACIÓN COMPARADA}

Para esclarecer un poco más el panorama jurídico de las franquicias, es necesario profundizar el tratamiento que le dan a esta figura comercial en otros países, en donde ya ha sido institucionalizada legalmente.

La simplicidad de la legislación que se propone, se puede comparar con las legislaciones de otros países, en donde los Estados Gubernamentales han demostrado el apoyo y la confianza que merece el sector, otorgándoles en algunos casos una ley propiamente de franquicias, en otros, el Estado los ha reconocido dentro de una ley ya existente, en otros casos, ha generado lineamientos especiales al respecto.

\section{Brasil}

En 1994, fue promulgada una legislación específica para el sector que pasó a regir las relaciones entre franquiciados y franquiciantes, mediante la Ley de Franquicias propiamente dicha. Durante la década del noventa, el sector alcanzó tasas de crecimiento impresionantes y ocupó inmediatamente la tercera posición en el ranking mundial de franquicias.

Ricardo Camargo, Director de la ABF (Asociación Brasilera de Franquicias), comenta que en base a la experiencia de Brasil, una ley no se convierte en un obstáculo para el desarrollo del sector, si es que se plantea como una ley marco, muy general. Algunos dicen que hay que esperar a que haya más desarrollo del sector y que el propio mercado lo demande; sin embargo, en Brasil después de la ley, se avanzó mucho en el sistema de franquicias, por lo que considero que una Ley de Franquicias puede servir como un elemento promotor y de soporte inicial, siempre y cuando no se sobreregule."12

\section{México}

Se insertó artículos relativos a la franquicia en su Ley de Propiedad Intelectual. La facturación de las franquicias es de aproximadamente de 85 mil millones de pesos anuales y da empleo directo a más de 500,000 personas. Conforme a estos mismos datos, el sector mantuvo la tendencia de años anteriores, creciendo en el año 2011 el 13\%. ${ }^{13}$

Actualmente se está discutiendo en el Senado Mexicano un proyecto de ley que pretende insertar todo un capítulo en el Código de Comercio, con una serie de artículos más especializados para el desarrollo del sector. Proyecto en el que consultoras, la AMF (Asociación Mexicana de Franquicias) y todos los agentes activos del sector están de acuerdo.

\section{España}

En España, las franquicias se regulan por el REAL DECRETO 419/2006 de 7 de abril, por el que se modifica el Real Decreto 2485/1998, de 13 de noviembre, relativo a la regulación del régimen de franquicia y el registro de franquiciadores.

Cabe resaltar, la importancia que se dio al legislar esta figura comercial, explicándose de la siguiente manera: "La experiencia demuestra que la mejora en la regulación del Registro puede reforzar su finalidad última de ser un instrumento eficaz de información y transparencia del mercado, lo que aconseja la

12 Ludeña, Yuly. Tesis "Conveniencia de una regulación jurídica para los sistemas de franquicias en el Perú”. Entrevista a especialistas.

13 ANFECA. Documento Electrónico. 
adaptación de esa reglamentación mediante la presente nor$m a " .{ }^{14}$

La similitud que guardan estas normas, es que todas regulan de una manera marco sobre los aspectos más importantes y generales de la franquicia, como son el concepto, las obligaciones de las partes, la COF y su obligatoriedad, el contrato, entre otros.

\section{Venezuela}

En Venezuela ya se han emitido ciertos elementos de especialidad para el sector franquicias. En Enero del año 2000, se dictaron los Lineamientos sobre Franquicias, dictados por PRO-
COMPETENCIA, que engloba un conjunto de normas dirigidas exclusivamente al sector.

Los lineamientos de evaluación de los contratos de franquicia, establecieron la posibilidad de que se permita, bajo ciertas condiciones, la realización de actividades en principio prohibidas, como "las representaciones territoriales exclusivas y las franquicias con prohibiciones de comerciar con otros productos".

\section{Argentina}

En Agosto del 2010, la Asociación Argentina de Franquicias $(\mathrm{AAF})$, se encontraba pidiendo que antes de fin de año, el proyecto de ley de franquicias fuese aprobado. Justificaban ello, debido a un doble problema: Que empresas anuncien sistemas de franquicias que no son tales; y que los derechos y obligaciones de las partes no tengan un marco específico. ${ }^{15}$

En este país ya se han visto casos idénticos en los que en una Sala dictan responsabilidad solidaria entre franquiciante y franquiciado; y en otras Salas no, debido a su naturaleza jurídica. Ello ha generado un caos jurídico respecto a los conflictos alrededor de la franquicia.

\section{Fuente: Portal FIAF.Facturación del sector franquicias por países}

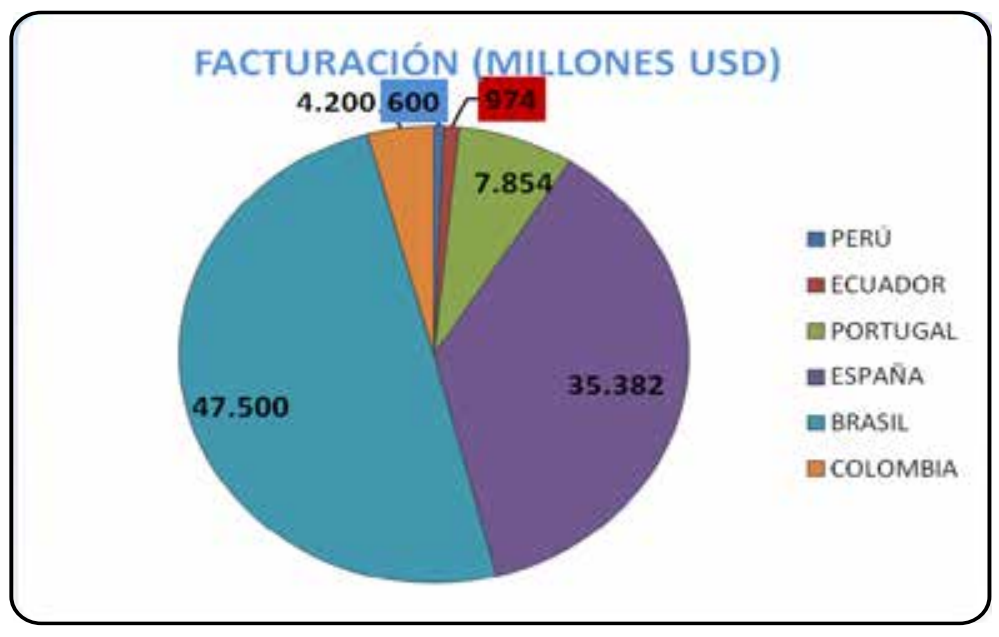

\section{Propuesta nORMATIVA}

En la actualidad, como ya se explicó no existe legislación que regule de manera especial las franquicias. El sistema que tenemos para regular este tipo de contratos es multirregulatorio. La idea es que exista una legislación especial para las franquicias en el Perú, de esta manera asegurar buenos contratos comerciales.

La idea de promover una legislación para las franquicias, es que ésta sea básica, una legislación marco, cuya función sería dar seguridad a las personas que no conocen de este tema, al contar con una ley se sentirían con más confian- za de apostar por este tipo de formato comercial.

De que una ley especial en el tema ayudaría a promover más el sector, no queda duda a pesar de existir diferentes opiniones al respecto:

1. Algunos opinan que legislar sería sinónimo de ahuyen-

\footnotetext{
14 LEY ESPAÑOLA DE FRANQUICIAS: REAL DECRETO 419/2006

15 www.aamf.com.ar: Portal Electrónico.
} 
tar el sector, de paralizarlo, ya que la franquicia es una figura comercial y por su naturaleza no debe ser regulada jurídicamente.

2. Otros dicen que debemos esperar a que el mercado exija una legislación, que existan conflictos, para pensar en una ley porque con esto ya quiere decir que la sociedad requiere un orden.

3. Otros, alegan que con las normas que tenemos es suficiente.

Frente a estas posturas, respondemos:

1. Ante lo primero, ahuyentar al sector con parámetros legales sería cierto si se sobrerregularía, si se trata de normativizar hasta el pequeño detalle, caso de Estados Unidos. Pero si se trata de una ley marco, que sólo dé los conceptos básicos y las pautas claras para un funcione el sector de manera más formal, definitivamente no paralizaría su crecimiento, mas al contrario, promovería el mismo.

2. Para la segunda idea, esperar que la sociedad lo requiera, esperar que las franquicias aumenten su necesidad de una legislación para cuando exista un número considerable de conflicto, parecen ser palabras de un administrador, de un economista, mas no de un abogado. Los abogados tienen claro que la ley tiene una función predictiva, esperar que existan un número de conflictos considerables, significaría verse en un aprieto, mayor carga procesal, dejar la resolución de estos casos en espera, buscar autoridades competentes del tema. Actualmente no existen siquiera juzgados o especialistas al respecto. Entonces esperar conflictos, es una decisión bastante floja y dejada.

3. Afirmar que con la legislación que tenemos basta, sería minorizar las opiniones de los mismos agentes activos del sector, los franquiciante nacionales $y$ extranjeros, que han expresado su voz de haber tenido conflictos y no haber quedado satisfechos con la decisión final. No se estaría tomando en cuenta, lo que inversionistas extranjeros sugieren para un mayor desarrollo de sus conceptos en nuestro país. Hasta ahora se ha podido manejar el tema de los conflictos entre las partes, pero si queremos un crecimiento del sector, es necesario una norma más especial.
Tener una ley especializada, aparte de generar un mayor desarrollo del sector, genera formalidad en el profesionalismo. Esto debido a que obligaría a todos los participantes a ser más ordenados, a estudiar más, a instruirse, a ser más transparentes. Lo que definitivamente fortalecerá el sistema en nuestro país a nivel de formalización y de crecimiento económico. Esto no es una simple suposición, sino que en los países legislados, este formato de negocio crece sostenidamente brindando posibilidades de inversión y desarrollo a los ciudadanos y pequeñas empresas.

En conclusión, la multirregulación con la que se ha estado manejando los contratos de franquicias, no será suficiente en los próximos años, ya que al crecer el sector, crecen por lógica los conflictos. Es así que se enmarca un modelo de legislación con los elementos básicos que requiere el mercado peruano de franquicias, para otorgar mayor seguridad jurídica a los agentes partícipes del sector y a manera de promocionar de manera confiable y transparente el sistema ante la ciudadanía.Lo que se propone es una legislación marco, normas claras que aseguren los principales elementos descritos a lo largo de la investigación, de manera de otorgar seguridad jurídica al sector y promocionarlo. La propuesta normativa se encuentra en la tesis realizada. 